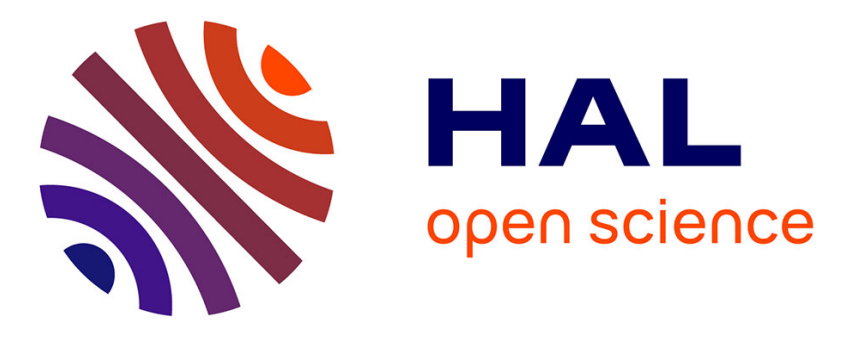

\title{
Autogenous deformations of cement pastes
}

Pierre Mounanga, Véronique Baroghel-Bouny, Ahmed Loukili, Abdelhafid Khelidj

\section{To cite this version:}

Pierre Mounanga, Véronique Baroghel-Bouny, Ahmed Loukili, Abdelhafid Khelidj. Autogenous deformations of cement pastes: Part I. temperature effects at early age and micro-macro correlations. Cement and Concrete Research, 2006, 36 (1), pp.110-122. 10.1016/j.cemconres.2004.10.019 . hal01005281

\section{HAL Id: hal-01005281 \\ https://hal.science/hal-01005281}

Submitted on 14 Oct 2017

HAL is a multi-disciplinary open access archive for the deposit and dissemination of scientific research documents, whether they are published or not. The documents may come from teaching and research institutions in France or abroad, or from public or private research centers.
L'archive ouverte pluridisciplinaire HAL, est destinée au dépôt et à la diffusion de documents scientifiques de niveau recherche, publiés ou non, émanant des établissements d'enseignement et de recherche français ou étrangers, des laboratoires publics ou privés. 


\title{
Autogenous deformations of cement pastes: Part I. Temperature effects at early age and micro-macro correlations
}

\author{
Pierre Mounanga, ${ }^{\mathrm{a}, *}$, Véronique Baroghel-Bouny ${ }^{\mathrm{b}}$, Ahmed Loukili ${ }^{\mathrm{c}}$, Abdelhafid Khelidj ${ }^{\mathrm{a}}$ \\ anstitut de Recherche en Génie Civil et Mécanique (GeM), UMR CNRS 6183-IUT de Saint-Nazaire, département Génie Civil, B.P. 420 , \\ 44606 Saint-Nazaire Cedex, France \\ ${ }^{\mathrm{b}}$ Laboratoire Central des Ponts et Chaussées, 58 Bd Lefebvre, F-75732 Paris Cedex 15, France \\ ${ }^{\mathrm{c}}$ GeM, UMR CNRS 6183-Ecole Centrale de Nantes, B.P. 92101, 44321 Nantes Cedex 3, France
}

\begin{abstract}
A micro-macro experimental study has been performed, from the end of mixing up to 2 years, on a set of plain cement pastes prepared with the same type I ordinary Portland cement (OPC) and various water-to-cement ratios (W/C), and cured at various constant temperatures. In this part I of the paper, volumetric autogenous shrinkage has been analysed in relation to various parameters characterizing the hydration process: chemical shrinkage, degree of hydration of the cement, $\mathrm{Ca}(\mathrm{OH})_{2}$ content and Vicat setting times, within the early-age period $(\leq 24 \mathrm{~h})$. The effects of the curing temperature (ranging from 10 up to $50{ }^{\circ} \mathrm{C}$ ) have in particular been investigated. Its effects recorded on both the rate and the magnitude of volumetric autogenous shrinkage vs. time have pointed out the irrelevance of the usual maturity concept to describe such phenomenon within the whole early-age period. An improved maturity concept has hence been proposed. It is based on separating the early-age period in different phases and on using chemical shrinkage data for the calculation of the apparent activation energy applied to the prediction of autogenous deformations occurring after the setting period. Furthermore, micro-macro relationships have been pointed out, illustrating in particular the determining role of $\mathrm{Ca}(\mathrm{OH})_{2}$.
\end{abstract}

Keywords: Cement paste; Early age; Hydration; Maturity concept; Shrinkage

\section{Introduction}

Predicting the early-age behaviour of cementitious materials has becoming a challenging task in concrete science and practice. This results from the fact that many properties of concrete structures are sensitive to the early-age characteristics of the material. Therefore, knowledge of these characteristics has much potential to improve construction quality and hence durability. In autogenous conditions and without loading, early-age volume changes of cementitious materials are usually assumed to include two components. One is the autogenous deformation related to the hydration

\footnotetext{
* Corresponding author. Tel.: +332401786 02; fax: +33240178160. E-mail address: pierre.mounanga@iutsn.univ-nantes.fr (P. Mounanga).
}

process and to the progressive hardening of the material. The second is the thermal dilation governed by the coefficient of thermal expansion of the material and the temperature changes associated with the exothermic nature of the hydration reactions of the cement. Both components can develop to a great extent, in particular in materials with low $\mathrm{W} / \mathrm{C}$, increasing thereby the cracking risks at early age. The maturity concept is usually applied in order to de-couple these two types of deformations and to predict thereafter autogenous deformations under realistic temperature conditions. This concept is based on the assumption that the temperature influence on the hydration rate (and associated properties) is independent of the degree of hydration. Nevertheless, several recent studies have shown that the rate and the magnitude of autogenous shrinkage of concrete, for a given degree of hydration, were influenced by the temperature history $[1,2]$. This questions the relevance of 
the usual maturity concept to account for temperature effects on autogenous deformations.

The purpose of the research reported in this paper (separated in two parts) is a better understanding of the mechanisms associated with the development of autogenous deformations in cementitious materials. In order to further investigate the relevance of the usual maturity concept, the effects of temperature (isothermal curing process) on various properties (volumetric autogenous shrinkage, but also chemical shrinkage, degree of hydration, $\mathrm{Ca}(\mathrm{OH})_{2}$ content, etc.) of cement pastes at early age $(\leq 24 \mathrm{~h})$ have been studied in this part I of the paper. Moreover, an improved maturity concept has been proposed and discussed. It consists in defining different phases-before and after setting - within the early-age period and affecting to each of them a different apparent activation energy. After the setting period, the apparent activation energy has been determined here through chemical shrinkage data.

\section{Experimental program, materials and test methods}

\subsection{Experimental program and materials}

The experimental study has been performed at early age $(\leq 24 \mathrm{~h})$ on a set of plain cement pastes prepared with the same type I OPC (CEM I 52.5, according to the EN 197-1 European standard) and distilled water. Volumetric autogenous shrinkage has been measured together with various parameters characterizing the hydration process (chemical shrinkage, degree of hydration of the cement, $\mathrm{Ca}(\mathrm{OH})_{2}$ content and Vicat setting times).

The $\mathrm{W} / \mathrm{C}$ of the cement pastes ranged from 0.25 up to 0.40 and the mixtures were submitted to an isothermal curing process at $10,20,30,40$ or $50{ }^{\circ} \mathrm{C}$. The cement contained $70.2 \% \mathrm{C}_{3} \mathrm{~S}, 7.8 \% \mathrm{C}_{2} \mathrm{~S}, 3.8 \% \mathrm{C}_{3} \mathrm{~A}$ and $6.0 \% \mathrm{C}_{4} \mathrm{AF}$
(Bogue calculation). Its loss on ignition was 2.3\% and its Blaine-specific surface area was $3320 \mathrm{~cm}^{2} \mathrm{~g}^{-1}$. The gypsum content was $5.2 \%$. The chemical composition and the particle size distribution of the cement are given in Ref. [3]. The cement was mixed in a 5-1 laboratory mixer for 1 min, before addition of distilled water and a further mixing period of $3 \mathrm{~min}$, in order to ensure a good homogeneity. As far as the curing temperature is concerned, the mixing water was heated or cooled on a case-by-case basis. This ensured a rapid equilibrium of the mixture at the required temperature.

\subsection{Volumetric autogenous shrinkage measurement}

The test method used here for volumetric autogenous shrinkage (also called external chemical shrinkage) measurement at early age is based on Archimedes' principle. It consists of measuring, by hydrostatic weighing, the buoyancy variations of a sample constituted by an elastic rubber (latex) membrane filled with cement paste (about 100-150 g) and immersed in a thermoregulated bath [4-6] (see Fig. 1a). The cement paste is introduced into the membrane immediately after casting and this membrane is closed using a thin stainless steel wire. The excess rubber is then cut and the sample is cleaned and weighed. Thereafter, the sample is placed on a nacelle hung from a balance and immersed immediately in the water bath at the required temperature $10,20,30,40$ or $50{ }^{\circ} \mathrm{C}\left( \pm 0.1{ }^{\circ} \mathrm{C}\right)$. The sample is not rotated. The accuracy of the balance is $0.0001 \mathrm{~g}$. Both the bath temperature and the mass of the system are continuously recorded from $30 \mathrm{~min}$ after watercement contact up to $24 \mathrm{~h}$.

It can be recalled here that the choice of latex membranes guarantees a good tightness with respect to the surrounding medium (at least during the test duration) and allows unrestrained deformations of the cement paste. In addition, the greatest care has been exercised to

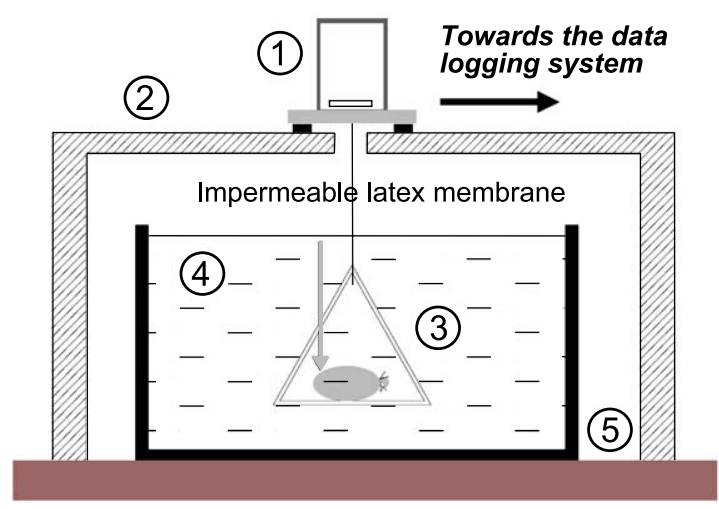

a)

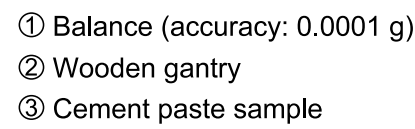

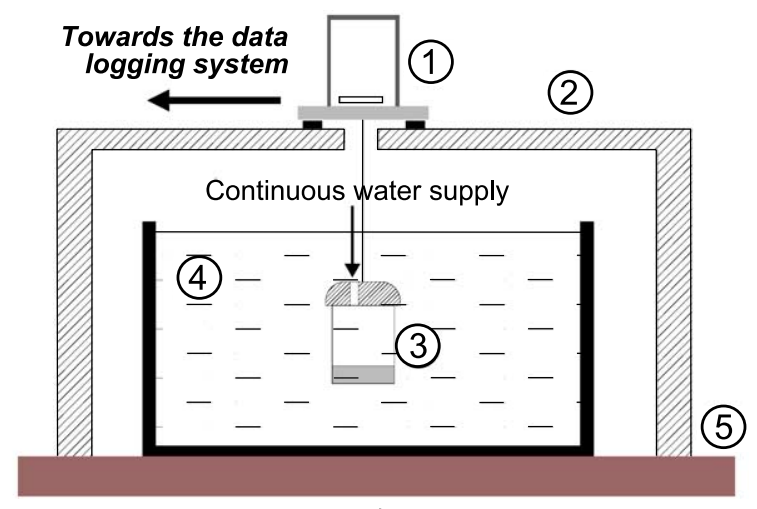

b)

(4) Thermo-regulated bath

(5) Anti-vibration frame (concrete structure)

Fig. 1. Scheme of the test devices used for volumetric autogenous shrinkage measurement (a) and chemical shrinkage measurement (b). 
evacuate air. The presence of air bubbles inside the membrane is indeed prejudicial, as the contraction pores, which form during the hydration process, can suck in this air and cause a reduction in the volume of the membrane that can wrongly be interpreted as shrinkage. Likewise, it is well known that bleeding makes the measurement of "true" shrinkage difficult to carry out $[5,6]$. In case of bleeding, which may occur with medium or high W/C, overestimated values of volumetric autogenous shrinkage can be measured. This may also explain why no swelling is generally observed when using this technique, even in the case of high $\mathrm{W} / \mathrm{C}$, and contrary to length change measurements [7] (see also part II of the paper). Therefore, in order to avoid the possible occurrence of bleeding in the experiments performed here, volume change measurements have been performed only on the cement pastes with $\mathrm{W} / \mathrm{C}=0.25$.

\subsection{Complementary investigations}

(Total) chemical shrinkage has been measured by means of a weighing method $[4,8]$ (see Fig. $1 \mathrm{~b}$ and part II of the paper). The evolution of both the non-evaporable water content and the calcium hydroxide content of the cement pastes has been monitored as a function of time (age) by means of thermogravimetric analysis (TGA). The non-evaporable water amount has been used to calculate the degree of hydration of the cement $(\alpha)$. A description of the test procedure can be found in Ref. [3] and in part II. The initial and final setting times of the cement pastes have been assessed by means of the Vicat (needle) test. The porosity and pore size distribution of the hardened cement pastes (hcp) have been determined by mercury intrusion porosimetry (MIP), after freeze-drying of the specimens, with an apparatus $\left(P_{\max }=400 \mathrm{MPa}\right)$ allowing the investigation of pore radii ranging from $1.8 \mathrm{~nm}$ up to $60 \mu \mathrm{m}$.

\section{Experimental results and discussion}

The assessment of chemical shrinkage, degree of hydration and $\mathrm{Ca}(\mathrm{OH})_{2}$ content data has already been described and analysed in a previous paper [3]. The present paper focuses more on the volumetric autogenous shrinkage of the cement pastes and on the correlations between this shrinkage and the chemical and microstructural evolutions of the pastes.

\subsection{Correlation between $\mathrm{Ca}(\mathrm{OH})_{2}$ content and setting times}

It has been shown in Ref. [3] that both the degree of hydration of the cement and the $\mathrm{Ca}(\mathrm{OH})_{2}$ content increased when temperature increased, for the cement pastes studied here $(\mathrm{W} / \mathrm{C}$ ranging from 0.25 up to 0.40 and curing temperature ranging from 10 up to $50{ }^{\circ} \mathrm{C}$ ). In addition, two main observations were made when plotting the calcium hydroxide content vs. the degree of hydration (ages below $24 \mathrm{~h}$ ). First, the curing temperature did not influence the correlation existing between $\mathrm{Ca}(\mathrm{OH})_{2}$ content and degree of hydration (see Fig. 2). Secondly, a threshold was exhibited around $\alpha=7 \%$, whatever the mixture, which corresponded to the appearance of $\mathrm{Ca}(\mathrm{OH})_{2}$ in solid phase (precipitation), as detected by TGA (see Fig. 3). Note that lime is already present under ionic form in the pore solution from few minutes after mixing. Moreover, from this threshold, the $\mathrm{Ca}(\mathrm{OH})_{2}$ content was linearly related to the degree of hydration, as pointed out in Fig. 2. These purely experimental findings were confirmed through a semi-empirical model based on analytical expressions describing the hydration process [3].

It is usually assumed that the lime concentration of the solution is the parameter controlling both the hydration and the setting process $[9,10]$. The formation of calcium hydroxide coincides with the acceleration period of the

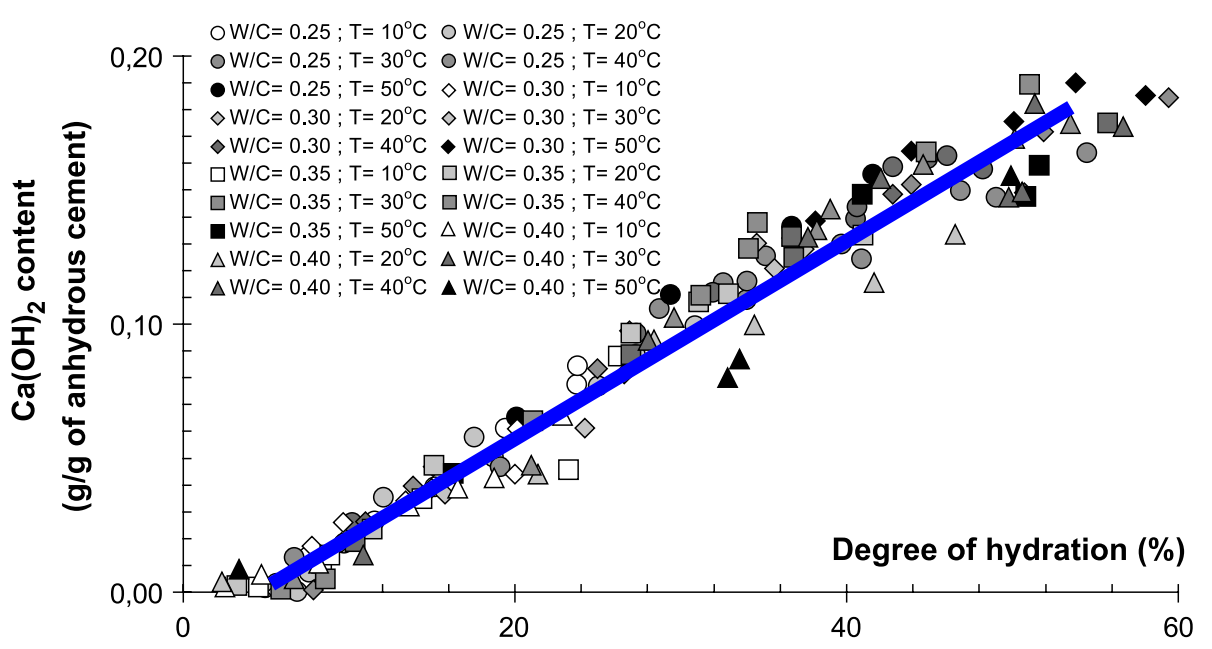

Fig. 2. $\mathrm{Ca}(\mathrm{OH})_{2}$ content of cement pastes with $\mathrm{W} / \mathrm{C}$ ranging from 0.25 to 0.40 and cured at $10,20,30,40$ or $50{ }^{\circ} \mathrm{C}$, as a function of the degree of hydration of the cement. 


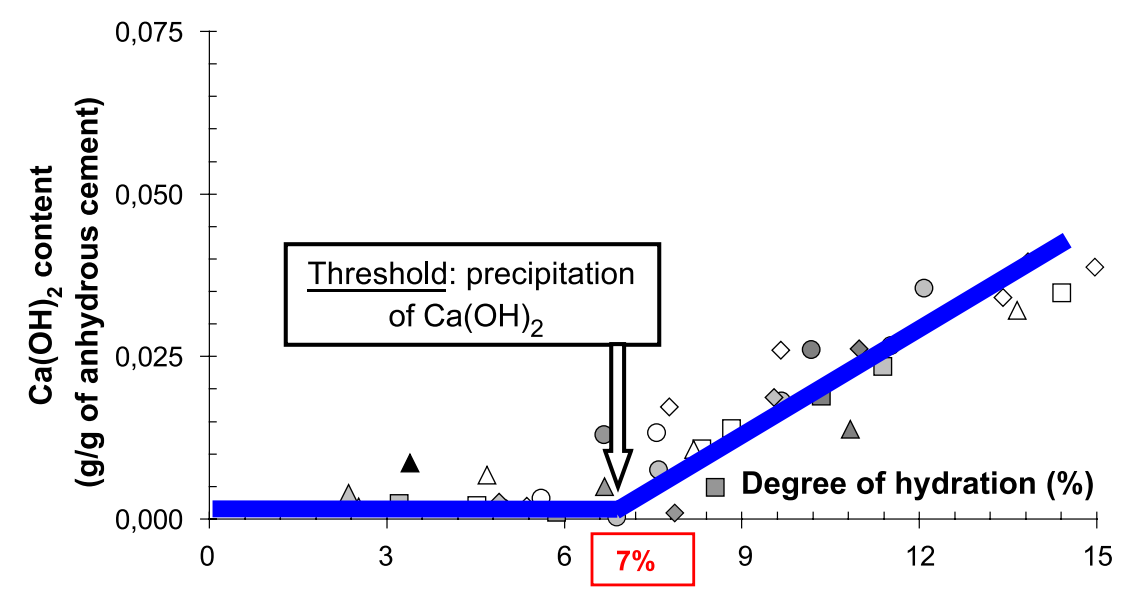

Fig. 3. Correlation between $\mathrm{Ca}(\mathrm{OH})_{2}$ content and degree of hydration. Zoom of Fig. 2 within the very early age range $(\alpha<15 \%)$. The symbol marks are the same as in Fig. 2.

hydration process [11]. At the beginning of this period, the calcium ion concentration of the liquid phase reaches a maximum. This induces the crystallization of $\mathrm{Ca}(\mathrm{OH})_{2}$. The resulting decrease in the calcium ion concentration of the liquid phase hence accelerates the dissolution of the cement compounds. Layers and clusters of $\mathrm{C}-\mathrm{S}-\mathrm{H}$ grow and interpenetrate, which induces at the macroscopic scale an increase in the material stiffness. Note that, before this stage, crystallization of AFt has already taken place $[11,12]$. It seems therefore relevant to confirm here this apparent link between the chemical evolution of the material (microscopic scale), which can be characterized in particular by an increase in the TGA calcium hydroxide amount, and the development at the macroscopic scale of its physical and mechanical properties (e.g. increase in stiffness). With this purpose, the ages corresponding to the respective chemical and (physical and) mechanical thresholds have been plotted on a same graph, as illustrated in Fig. 4 for cement pastes maintained at different isothermal curing temperatures and with $\mathrm{W} / \mathrm{C}=0.25,0.30,0.35$ and 0.40 . As regards the chemical threshold $\left(\mathrm{Ca}(\mathrm{OH})_{2}\right.$ precipitation), the ages were obtained by linear interpolation between two experimental plots. The (physical and) mechanical threshold has been deduced from the initial and final Vicat setting times (mean values of three Vicat needle tests). Given the Vicat test accuracy $( \pm 10 \mathrm{~min})$, it can be said that, in most of cases, the appearance of $\mathrm{Ca}(\mathrm{OH})_{2}$ detected by TGA coincides rather well with the

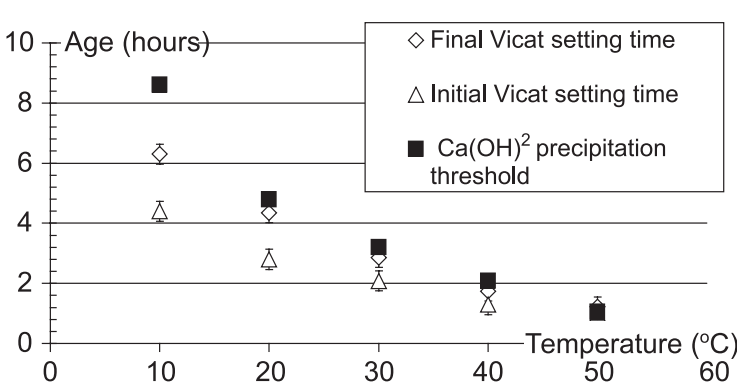

a) $\mathrm{W} / \mathrm{C}=0.25$

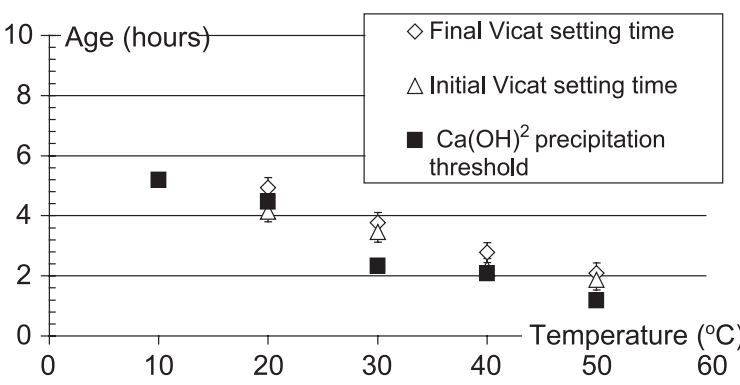

c) $\mathrm{W} / \mathrm{C}=0.35$

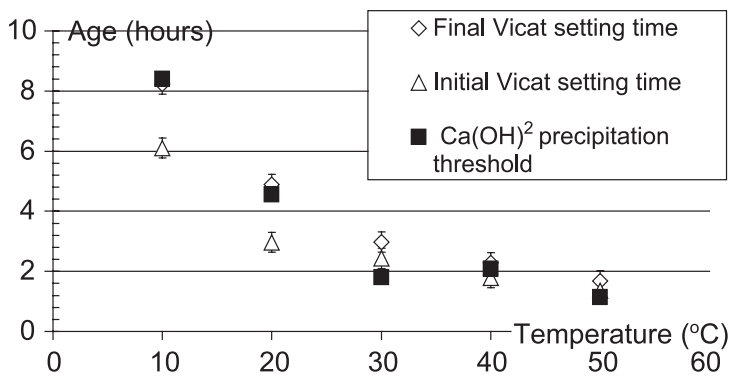

b) $W / C=0.30$

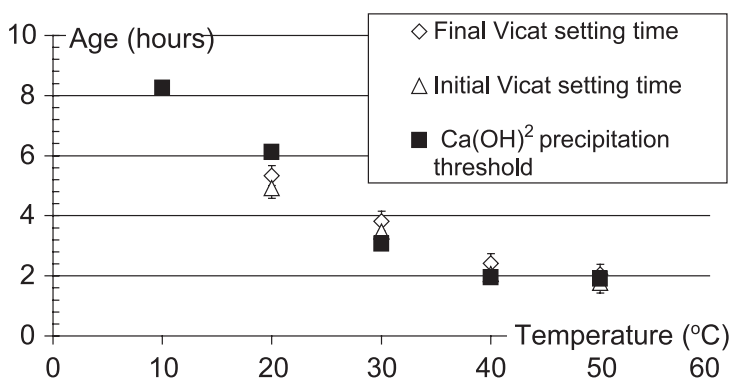

d) $\mathrm{W} / \mathrm{C}=0.40$

Fig. 4. Comparison between the initial and final setting times obtained from Vicat needle and the chemical threshold (precipitation of calcium hydroxide detected by TGA), for cement pastes cured at various temperatures, for $\mathrm{W} / \mathrm{C}=0.25$ (a), $\mathrm{W} / \mathrm{C}=0.30$ (b), W/C $=0.35$ (c) and $\mathrm{W} / \mathrm{C}=0.40$ (d). 
setting times given by the Vicat needle. The consistency is particularly good at $T=40$ and $50{ }^{\circ} \mathrm{C}$ (the chemical threshold is found between initial and final setting times), whatever the water-to-cement ratio, as increasing the curing temperature yields a decrease in the initial and final Vicat setting times and in the respective setting period (see Fig. 4). This last result was expected given the temperature-activated nature of the hydration process, usually described by an Arrhenius law: when the temperature increases, the hydrate production rate increases and the solid network required to resist the penetration of the falling Vicat needle is obtained more rapidly. At lower temperatures, the $\mathrm{Ca}(\mathrm{OH})_{2}$ precipitation threshold seems closer to the final setting time. The results displayed in Fig. 4 show the effective link existing between the chemical evolution of the material (as described here by TGA $\mathrm{Ca}(\mathrm{OH})_{2}$ content) and its gain in mechanical stiffness (as described here by Vicat test). More precisely, $\mathrm{Ca}(\mathrm{OH})_{2}$ precipitation could be considered as a relevant chemical indicator of the setting of cement pastes. In addition, these results enhance the notion of threshold as regards the material structure evolution, which separates the "fluid" state from the "solid" state.

\subsection{Temperature effects on volumetric autogenous shrink- age-proposal for an improved maturity concept}

The volumetric autogenous shrinkage of the cement pastes with $\mathrm{W} / \mathrm{C}=0.25$ and cured at various temperatures $\left(10,20,30,40\right.$ or $\left.50^{\circ} \mathrm{C}\right)$ is plotted vs. the age in Fig. 5, from initial Vicat setting time up to $24 \mathrm{~h}$. In order to select the same hydration state as the time reference for every cement paste, the initial Vicat setting time has been taken as the zero point on the time scale of the curves. Such an initialisation of the deformations is required, in order to enable the comparison of their magnitude. Each plot is obtained from the mean value of three samples. The initial slope of these curves (rate) clearly increases with increasing temperature.
Moreover, each plot displays a first phase that ends by a knee-point. From this knee-point, the curves start to flatten. This knee-point and the subsequent drastic reduction in autogenous shrinkage are usually attributed to the formation of a semi-rigid (self-supporting) skeleton of interconnected hydration products, i.e. a load-bearing microstructure strong enough to resist the contracting forces created by chemical shrinkage [5]. In addition, this time may also correspond to a significant build-up of self-desiccation. But it is not elucidated yet whether self-desiccation begins at this moment, or as early as just few minutes after casting, in very low $\mathrm{W} / \mathrm{C}$ cement pastes. The latter case means that self-desiccation would start far before setting (e.g. at the mineral suspension-solid transition [13]), even if its consequences on external deformations are only visible later (i.e. when this process becomes prominent, see part II and Ref. [7]).

Fig. 5 shows that at $T=50{ }^{\circ} \mathrm{C}$ the knee-point is reached more rapidly than at the other temperatures, but the "ultimate" (at $24 \mathrm{~h}$ ) value of autogenous shrinkage is lower than the value reached at $T=40{ }^{\circ} \mathrm{C}$. This decrease in the magnitude, when the temperature increases from $T=40$ to $50{ }^{\circ} \mathrm{C}$, is probably the result of various chemical, physical and microstructural changes. First, slight changes in the chemical composition, stability and structure of the hydration products (in particular the $\mathrm{C}-\mathrm{S}-\mathrm{H}$ ) can be expected from an exposure to relatively high temperatures during their formation, according to the literature. In particular, it is well known that this favours the formation of inner $\mathrm{C}-\mathrm{S}-\mathrm{H}$. Likewise, an increase in the polymerisation of the silicate network of the $\mathrm{C}-\mathrm{S}-\mathrm{H}$ (increase in the length of the chains) has been recorded by Jennings $[14,15]$, while dimeric silicate species predominate in the $\mathrm{C}-\mathrm{S}-\mathrm{H}$ during the first $24 \mathrm{~h}$ and for $\mathrm{W} / \mathrm{C}=0.24-0.25$, at room temperature [16]. In addition, a link between changes in the $\mathrm{C}-\mathrm{S}-\mathrm{H}$ gel structure and the deformations of cement pastes has also been pointed out in the literature: a temperature rise reduces shrinkage in partic-

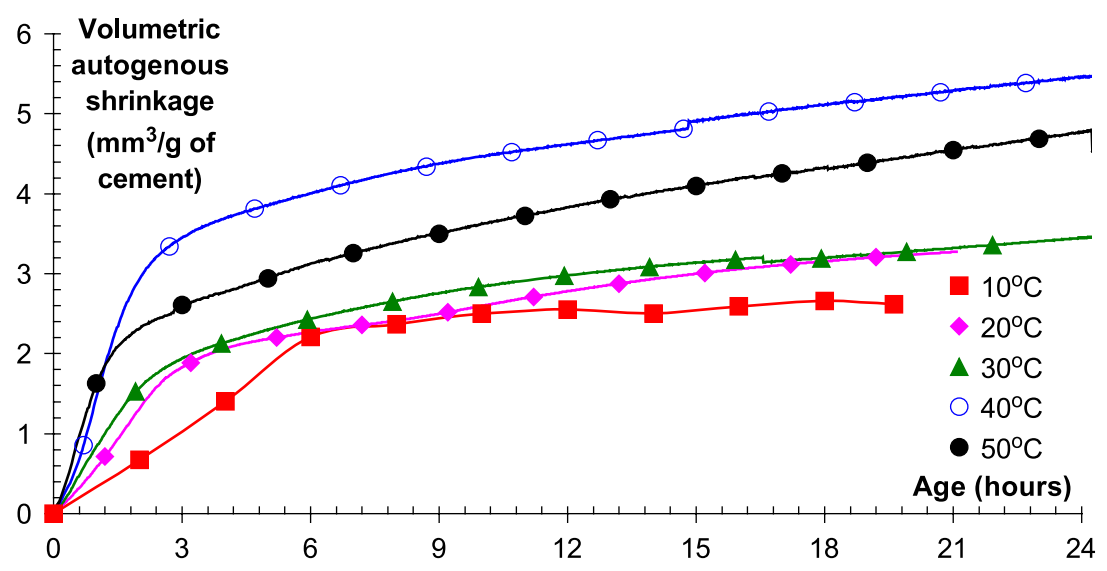

Fig. 5. Volumetric autogenous shrinkage vs. age for cement pastes with $\mathrm{W} / \mathrm{C}=0.25$ and cured at $10,20,30,40$ or $50{ }^{\circ} \mathrm{C}$ (zero point of the time scale: $t_{0}=$ initial Vicat setting time). 
ular because high temperature pre-shrinks the low-density C-S-H (see Refs. [14,15]). This latter point was experimentally demonstrated by Mak et al. [17], who found that a moderate temperature rise of $15{ }^{\circ} \mathrm{C}$ had a significant impact in reducing the early-age autogenous shrinkage of low W/C-ratio concretes to a level between $25 \%$ and $50 \%$. Secondly, thermodynamic (physical) effects can be expected: in materials with low W/C, self-desiccation occurs early and may contribute hence to a great extent to the recorded shrinkage. As the liquidvapour equilibrium governed by Kelvin(-Laplace) law, at the origin of this process, is temperature-dependent, the measured shrinkage value will consequently be temperature-dependent. Finally, changes in the distribution of hydrate clusters and consequently of inter-cluster voids are expected, as a result of the previously mentioned effects or additional ones. The pore structure of cement pastes hydrated at relatively high temperature is indeed modified, as depicted in Fig. 6. For example, it is reported in Ref. [18] that a more porous and continuous pore structure is formed when curing occurs at elevated temperatures (see also Ref. [19]). The rapid formation of inner C-S-H hinders the hydration process: the filling of the capillary pores is less efficient.

These experimental results clearly show the irrelevance of the usual maturity concept, based on a single apparent activation energy, for describing and predicting the evolution of autogenous deformations of cement pastes within the whole early-age period and for realistic temperature histories (in particular above $40{ }^{\circ} \mathrm{C}$ ). This finding is in agreement with Turcry et al. [20]. In this last reference, the authors defined the temperature range $\left(10-40{ }^{\circ} \mathrm{C}\right)$ where the maturity concept could be applied and pointed out that above $40{ }^{\circ} \mathrm{C}$ this concept was unable to predict the evolution of autogenous deformations.

Plotting now the volumetric autogenous shrinkage vs. the degree of hydration reveals the existence of a kneepoint, for 10,20 and $30{ }^{\circ} \mathrm{C}$, located around $\alpha=7 \%$ (see Fig. 7), which matches the chemical threshold (calcium

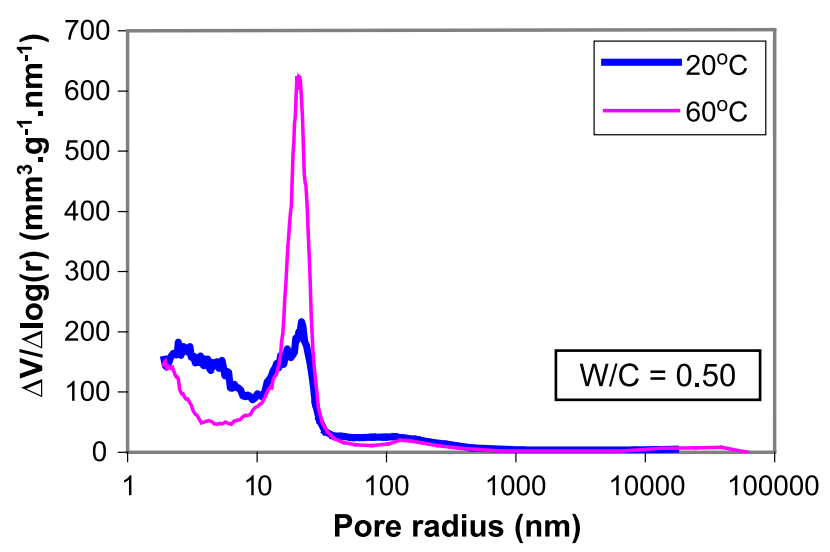

Fig. 6. Pore size distribution measured by MIP on hep with $\mathrm{W} / \mathrm{C}=0.50$, after 28-day curing at 20 or $60{ }^{\circ} \mathrm{C}$ and freeze-drying. hydroxide precipitation detected by TGA) previously pointed out in Fig. 3. This threshold could not be observed at 40 or $50{ }^{\circ} \mathrm{C}$ because the first measurement of $\alpha$ was too late at these temperatures. Beyond this threshold, the curves exhibit an almost parallel evolution. This means that the same degree of hydration increment leads to the same shrinkage increment for the various temperatures investigated. Therefore, beyond this threshold relative to the degree of hydration, the autogenous shrinkage of cement pastes is directly linked to their chemical evolution (degree of hydration). In order to enhance this finding, autogenous shrinkage data have been plotted in Fig. 8 vs. the degree of hydration, when taking $\alpha=7 \%$ as reference. The plots displayed in Fig. 8 have been obtained as follows: for each temperature, the measured shrinkage values have been lowered by the shrinkage values recorded at $\alpha=7 \%$ (given by the intersection between $y$-axis and the perpendicular to the $\mathrm{A}^{\prime} \mathrm{A}^{\prime \prime}$ line drawn in Fig. 7). Fig. 8 exhibits a linear correlation between autogenous shrinkage and degree of hydration, from $\alpha=7 \%$ (this means before the knee-point, see Fig. 7 in part II) up to $\alpha=50 \%$, except some scatter at very early age indicated by a circle in the figure. This scatter can be attributed, on the one hand, to the difficulty to ensure an appropriate accuracy in the TGA detection when very few amounts of hydration products are present and, on the other hand, to the possible influence of other parameters.

The linear fit displayed in Fig. 8 between autogenous shrinkage and degree of hydration, from $\alpha=7 \%$ up to $\alpha=50 \%$ and from 10 up to $50{ }^{\circ} \mathrm{C}$, could appear inconsistent with the results shown in Fig. 5. On the one hand, the ranking $\left(10<20<30<50<40{ }^{\circ} \mathrm{C}\right)$ of the plots "autogenous shrinkage vs. age" from initial Vicat setting time up to 24 $\mathrm{h}$ prevents applying the usual maturity concept. On the other hand, the plot "autogenous shrinkage vs. $\alpha$ " from $\alpha=7 \%$ (located at or after the final Vicat setting time, see Fig. 4) up to $\alpha=50 \%$ can be fitted by a unique linear function within the whole temperature range investigated, allowing the use of the maturity concept within this range of $\alpha$. The contradiction is only apparent. It lies in the fact that the maturity concept is not suitable to describe the temperature effects on autogenous deformations within the whole early-age period $0-24 \mathrm{~h}$, while it is yet possible to separate this period in different phases, in order to assign a different value of apparent activation energy and to apply the maturity concept within each of these phases. Such an approach has already been proposed by Turcry et al. [20]. Here, on the basis of the experimental data, the following preliminary partition can be proposed: the first phase will take place before final Vicat setting time (very early age) and the second phase will correspond to the range between final Vicat setting time and $24 \mathrm{~h}$. Given the experimental results and the fact that the first phase includes the setting period, great difficulties can be expected for applying rigorously 


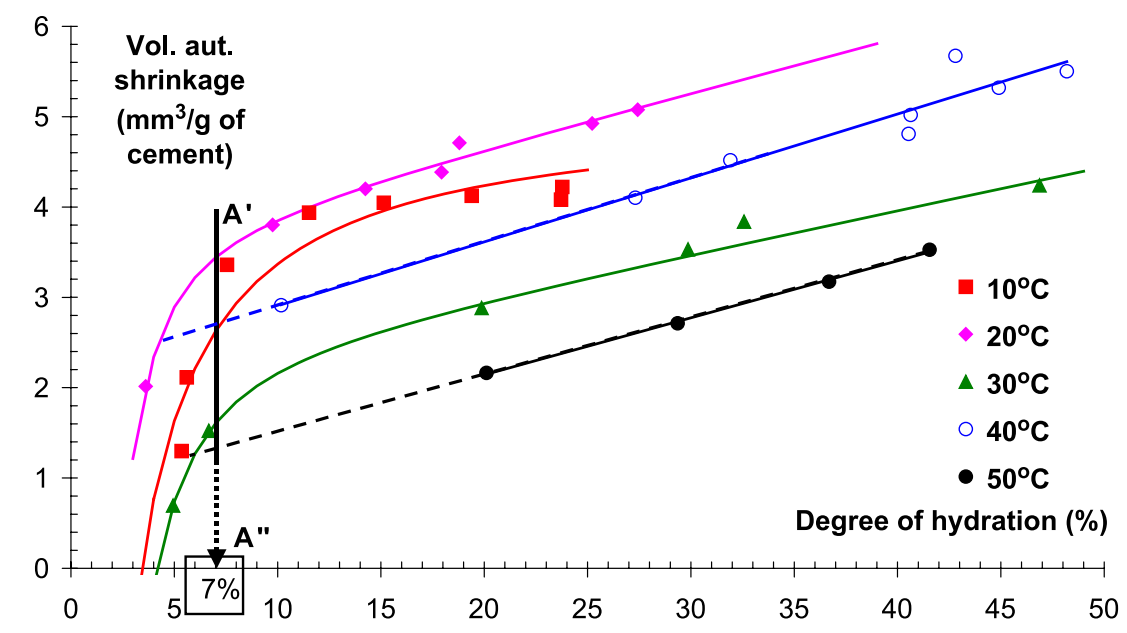

Fig. 7. Volumetric autogenous shrinkage vs. degree of hydration for cement pastes with $\mathrm{W} / \mathrm{C}=0.25$ and cured at $10,20,30,40$ or $50{ }^{\circ} \mathrm{C}$.

the maturity concept and to calculate a single value of apparent activation energy throughout this phase. Therefore, the first phase will not be investigated further in this paper. As far as the second phase is concerned, a finer partitioning may be required, in order to insulate the range where the maturity concept could be rigorously applied and where the proposed approach could be validated.

\subsection{Calculation of apparent activation energy from} chemical shrinkage data-validation of the improved maturity concept

In order to confirm the validity after the final Vicat setting time of the improved maturity concept proposed in the previous section, the approach has been applied to the experimental autogenous shrinkage results discussed in this paper. The modified Arrhenius law proposed by Hansen and Pedersen in 1977 [21] has been used, in order to calculate the so-called equivalent time. This law has indeed received the most widespread confirmation [22]. The equivalent time $t_{\mathrm{e}}$, defined as the time required at the reference temperature $T_{\text {ref }}\left({ }^{\circ} \mathrm{C}\right)$ for the cement paste to achieve the same level of development as under the influence of the actual temperature history, is thus given by Eq. (1):

$t_{\mathrm{e}}=\int_{0}^{t} \exp \left[\frac{E_{\mathrm{a}}}{R} \cdot\left(\frac{1}{\left(273+T_{\text {ref }}\right)}-\frac{1}{(273+T(t))}\right)\right] \mathrm{d} t$

where $E_{\mathrm{a}}$ is the apparent activation energy of the material ( $\mathrm{J} /$ $\mathrm{mol}), R$ the gas constant $(8.314 \mathrm{~J} / \mathrm{mol} / \mathrm{K})$ and $T$ the actual temperature $\left({ }^{\circ} \mathrm{C}\right) \cdot T_{\text {ref }}$ is usually taken as $20^{\circ} \mathrm{C}$, according to European practice.

The apparent activation energy $E_{\mathrm{a}}$ appears as a keyparameter in Eq. (1). Its apparent feature lies in the fact that it is commonly used to describe multi-reaction processes, whereas its initial definition was related to a single chemical reaction. This activation energy can be

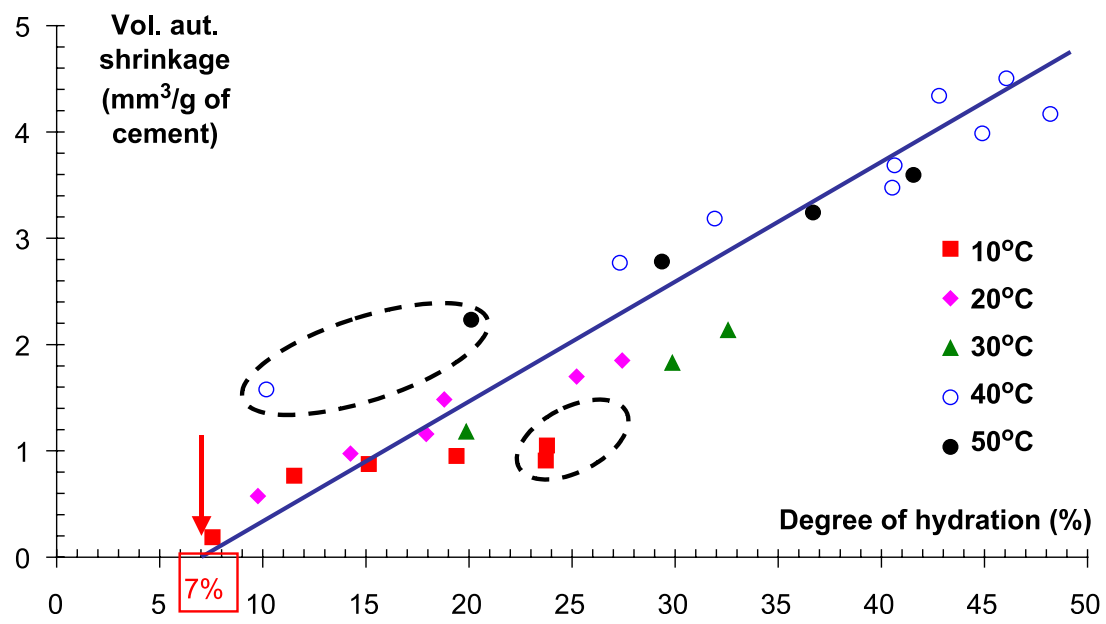

Fig. 8. Volumetric autogenous shrinkage between $\alpha=7 \%$ and $\alpha=50 \%$, for cement pastes with $\mathrm{W} / \mathrm{C}=0.25$ and cured at $10,20,30,40$ or $50{ }^{\circ} \mathrm{C}$. The reference for the shrinkage values is the intersection between $y$-axis and the perpendicular to the $\mathrm{A}^{\prime} \mathrm{A}^{\prime \prime}$ line drawn in Fig. 7, for each temperature. 
calculated from Eq. (2), which has been theoretically demonstrated in $[23,24]$ :

$\ln \left(\frac{\Delta \alpha}{\Delta t}\right)=-\frac{E_{\mathrm{a}}}{R} \cdot\left(\frac{1}{273+T_{0}}\right)+$ constant

where $T_{0}$ is the temperature $\left({ }^{\circ} \mathrm{C}\right)$ of the paste under isothermal conditions and $\Delta t$ is the time required to increase the degree of hydration with an increment $\Delta \alpha$ at $T_{0}$.

In addition, according to the literature, (total) chemical shrinkage of cement pastes and degree of hydration of cement are linearly linked $[25,26,8,3]$. The time-derivative of such a linear relationship reads (see Eq. (3)):

$\frac{\Delta\left(\Delta V_{\text {chem }}(t)\right)}{\Delta t}=\frac{\Delta \alpha}{\Delta t}$

where $\Delta\left(\Delta V_{\text {chem }}\right) / \Delta t\left(\mathrm{~mm}^{3} / \mathrm{g} / \mathrm{s}\right)$ is the slope of the chemical shrinkage vs. age plot. Including Eq. (3) in Eq. (2) yields Eq. (4):

$\ln \left(\frac{\Delta\left(\Delta V_{\text {chem }}\right)}{\Delta t}\right)=-\frac{E_{\mathrm{a}}}{R} \cdot\left(\frac{1}{273+T_{0}}\right)+$ constant

Hence, according to Eq. (4), $E_{\text {a }}$ can directly be assessed from chemical shrinkage data. Here, the experimental values discussed in Ref. [3] and recalled in Fig. 9 are used. In Fig. 9, the chemical shrinkage data have been initialised at the initial Vicat setting time for the same reason as that mentioned in Section 3.2 in the case of autogenous shrinkage.

The calculation of $E_{\mathrm{a}}$ has been performed in three steps (A, $\mathrm{B}$ and $\mathrm{C}$ ), as summarised in Table 1. After approaching the

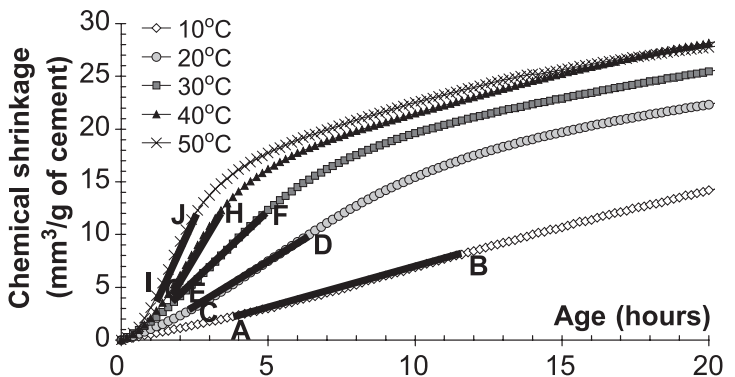

a) $\mathrm{W} / \mathrm{C}=0.25$

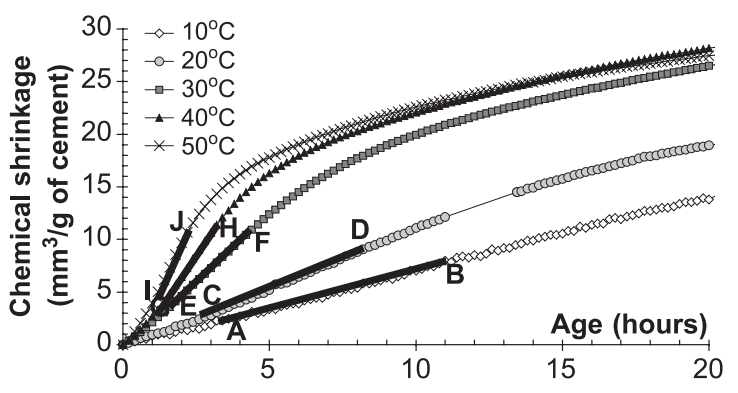

c) $W / C=0.35$
Table 1

Algorithm for the calculation of the apparent activation energy $E_{\mathrm{a}}$ based on chemical shrinkage measurements

A. Functional representation of the chemical shrinkage plots $\Delta V_{\text {chem }}=f(t)$ for each isothermal curing regime

B. Calculation of the derivatives of the chemical shrinkage functions and determination of $\left[\Delta\left(\Delta V_{\text {chem }}\right) / \mathrm{d} t\right]_{\text {max }}$ for each curve

C. Arrhenius plotting and determination of the apparent activation energy $E_{\mathrm{a}}$

chemical shrinkage plots by polynomial functions (step A), the derivatives of these functions have been determined (step B) (see Fig. 10, for cement pastes with $\mathrm{W} / \mathrm{C}=0.25$ ). The derivative curves, which have the same shape as hydration heat flux curves obtained by isothermal calorimetry (see Refs. $[27,28]$, for example), can be divided into two main stages. The first (ascending) stage corresponds to a constant acceleration of chemical shrinkage. The second (descending) stage indicates a reduction in the chemical shrinkage rate. The maximum on the derivative curves, which corresponds to the inflexion point on the chemical shrinkage curves, is usually interpreted as the starting point of the diffusion-controlled hydration process. This process occurs after the nucleationgrowing process, when the thickness of the $\mathrm{C}-\mathrm{S}-\mathrm{H}$ layers reduces the accessibility to the unreacted core of the grains $[29,11]$. It has been shown in the literature that an Arrhenius law was not suitable to describe correctly the temperature sensitivity within the second stage $[28,19]$. Therefore, the descending portion of the derivative curves has not been taken into account here for the calculation of $E_{\mathrm{a}}$. The value of the term $\Delta\left(\Delta V_{\text {chem }}(t)\right) / \Delta t$ appearing in Eq. (4) has been

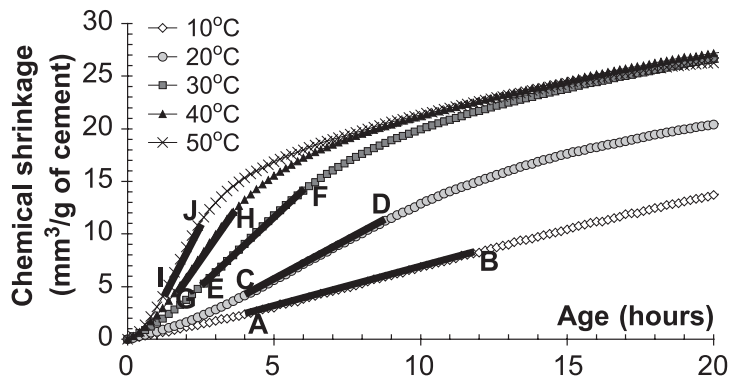

b) $\mathrm{W} / \mathrm{C}=0.30$

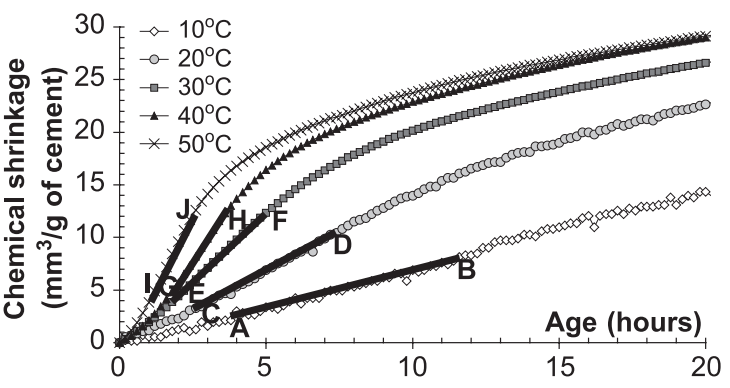

d) $W / C=0.40$

Fig. 9. Chemical shrinkage vs. age for cement pastes cured at $10,20,30,40$ or $50{ }^{\circ} \mathrm{C}$, with $\mathrm{W} / \mathrm{C}=0.25$ (a), 0.30 (b), 0.35 (c) and 0.40 (d) (zero point of the time scale: $t_{0}=$ initial Vicat setting time). 


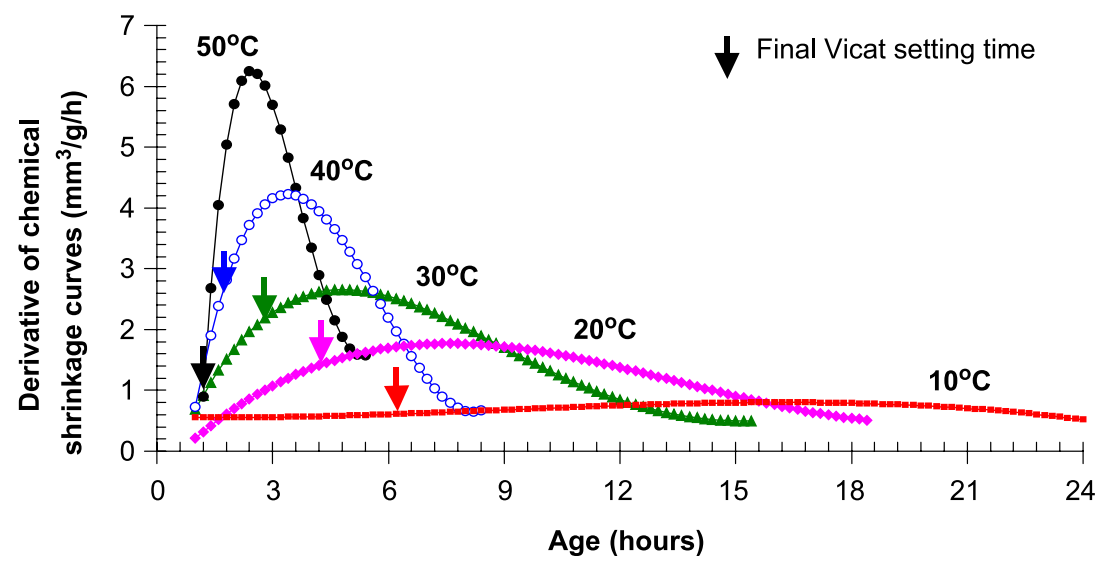

Fig. 10. Derivative curves of chemical shrinkage vs. age plots for cement pastes with W/C $=0.25$ and cured at $10,20,30,40$ or $50{ }^{\circ} \mathrm{C}$.

determined at the maximum of the derivative plots $\left[\Delta\left(\Delta V_{\text {chem }}(t)\right) / \Delta t\right]_{\max }$, through the initial slope of the chemical shrinkage curves (see Fig. 9). These initial slope values are reported in Table 2 and the best-fit linear regression of the experimental plots according to Eq. (4) are illustrated in Fig. 11 (an overall $r^{2}$ value $\geq 0.98$ was achieved) (step C). The $E_{\mathrm{a}}$ values deduced from Eq. (4) and Fig. 11 are reported in Table 3, where they are compared, in the case of $\mathrm{W} / \mathrm{C}=0.25$, to the values calculated by the "Vicat setting time method" for the same type of cement (CEM I 52.5) and already published [20,30]. A rather good agreement is observed, between the results obtained here after the final Vicat setting time, and the published values corresponding to the range between initial and final Vicat setting times.

The volumetric autogenous shrinkage results have then been plotted vs. the equivalent time computed according to Eq. (1) with the $E_{\mathrm{a}}$ values reported in Table 3, from the final Vicat setting time (according to the improved maturity concept proposed in Section 3.2). It can be seen in Fig. 12 that the application of the maturity concept provides mitigated results. In front of these results, a finer partitioning in three phases of the range (final Vicat setting time-24 h) can be proposed:

1. From the final Vicat setting time up to an equivalent time of $2 \mathrm{~h}$.

The five curves follow a similar trend (see Fig. 12). It can thus be deduced that this phase can quite well

Table 2

Values of the initial slope of the chemical shrinkage vs. age plots for the cement pastes with $\mathrm{W} / \mathrm{C}=0.25,0.30,0.35$ or 0.40 and cured at $10,20,30$, 40 or $50{ }^{\circ} \mathrm{C}$ (see Fig. 9)

\begin{tabular}{llllll}
\hline W/C & \multicolumn{5}{l}{ Initial slope $\left(\mathrm{mm}^{3} \mathrm{~g}^{-1} \mathrm{~h}^{-1}\right)$} \\
\cline { 2 - 6 } & $10{ }^{\circ} \mathrm{C}$ & $20{ }^{\circ} \mathrm{C}$ & $30{ }^{\circ} \mathrm{C}$ & $40{ }^{\circ} \mathrm{C}$ & $50{ }^{\circ} \mathrm{C}$ \\
& $(\mathrm{AB})$ & $(\mathrm{CD})$ & $(\mathrm{EF})$ & $(\mathrm{GH})$ & $(\mathrm{IJ})$ \\
\hline 0.25 & 0.74 & 1.80 & 2.75 & 4.59 & 6.50 \\
0.30 & 0.72 & 1.48 & 2.65 & 3.94 & 5.81 \\
0.35 & 0.71 & 1.19 & 2.59 & 4.17 & 5.60 \\
0.40 & 0.78 & 1.49 & 2.66 & 4.12 & 5.73 \\
\hline
\end{tabular}

be predicted by the maturity concept. This is the period where chemical shrinkage is the main component of autogenous deformations of cement pastes (see Fig. 14). As the maturity concept was successfully applied to the initial slope of the chemical shrinkage curves (see Fig. 11 ), it is not surprising that this concept gives also good results within this phase for autogenous shrinkage data.

2. "The knee-point period".

The $40{ }^{\circ} \mathrm{C}$-curve diverges markedly from the other curves and reaches a magnitude $60 \%$ higher than the other values (see Fig. 12). Except for the tests performed at 20 or $30{ }^{\circ} \mathrm{C}$, the maturity concept does not allow a correct prediction of the autogenous deformations within this phase. This can be explained by the complexity of the phenomena that take place (concomitant occurrence and competition between Le Chatelier's contraction, matrix hardening, self-desiccation, etc.) and their divergence from an Arrhenius law. According to the literature and as previously seen, the knee-point is indeed assumed as a transition point, separating the period where chemical shrinkage is the prominent component of autogenous deformations, from the period where self-desiccation shrinkage is the prominent component (see Section 3.2, part II and Refs. [5,31]).

3 . From an equivalent time of about 6-24 h.

The evolution of autogenous shrinkage is linear and the curves are rather parallel for the various temperatures studied (except $10^{\circ} \mathrm{C}$ ) (see Fig. 12). In order to clarify this observation, the autogenous shrinkage data have been initialised at an equivalent time of $6 \mathrm{~h}$ (i.e. after the "kneepoint period", see Fig. 13). As expected, the 20, 30, 40 and $50{ }^{\circ} \mathrm{C}$ curves then obtained are rather well superimposed. This illustrates that the maturity concept provides good results within these temperature and equivalent time ranges: experimental autogenous volume changes can correctly be predicted. As far as the $10{ }^{\circ} \mathrm{C}$ curve is concerned, a drastically lower "ultimate" value is reached. This temperature effect may be attributed to the various chemical, physical and microstructural changes already 


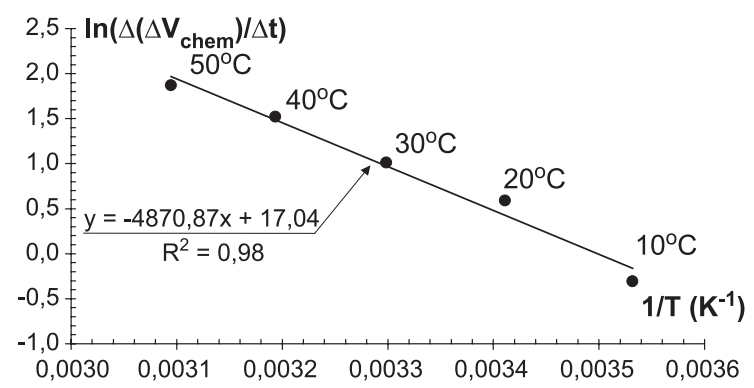

a) $\mathrm{W} / \mathrm{C}=0.25$

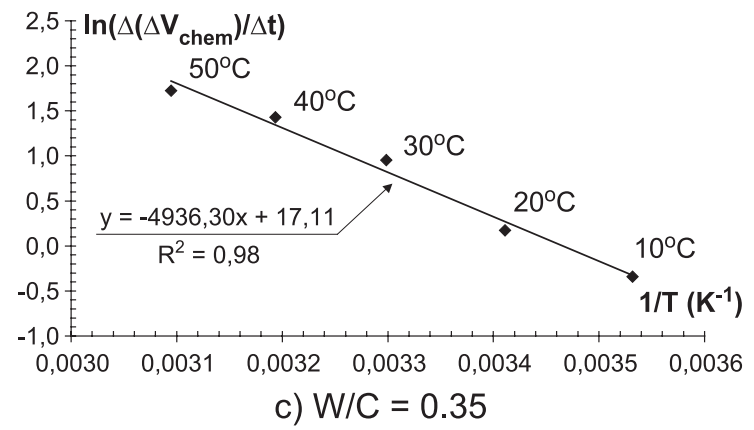

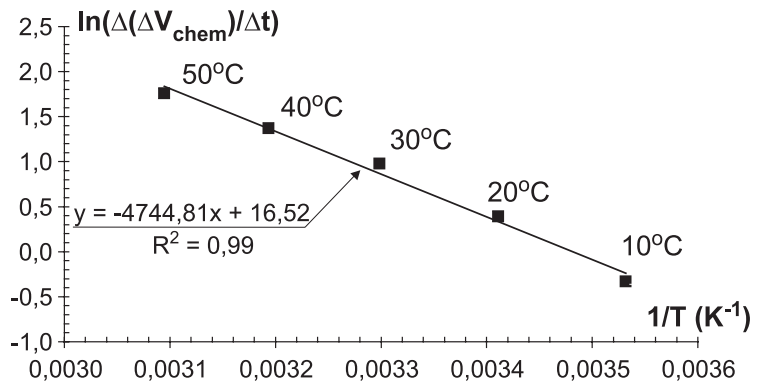

b) $\mathrm{W} / \mathrm{C}=0.30$

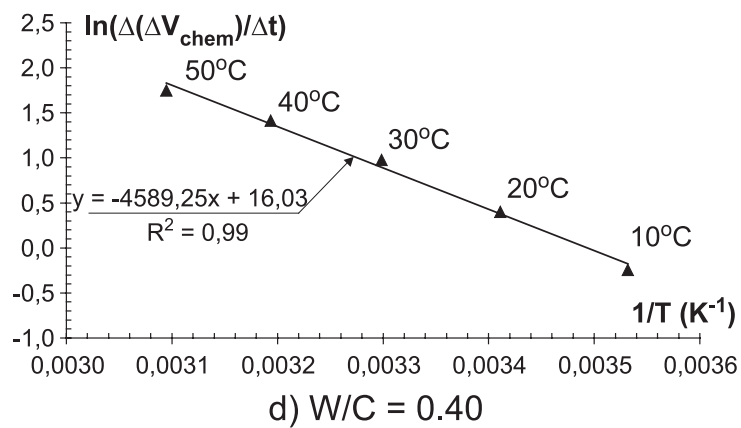

Fig. 11. Best-fit linear regression according to Eq. (4) for cement pastes with $\mathrm{W} / \mathrm{C}=0.25$ (a), 0.30 (b), 0.35 (c) and 0.40 (d) and cured at $10,20,30,40$ or $50{ }^{\circ} \mathrm{C}$.

mentioned in this paper (see also Ref. [32]) and to the low hydration level reached with $\mathrm{W} / \mathrm{C}=0.25$ at a curing temperature of $10{ }^{\circ} \mathrm{C}$, even after $24 \mathrm{~h}$ (see Ref. [3], for comparison with higher curing temperatures and W/C).

Finally, these results illustrate the difficulty in applying the maturity concept (even improved) within a broad temperature range to early-age autogenous shrinkage of cement pastes, even after the final Vicat setting time. The "knee-point period" appears as the most critical phase. After the "knee-point period", when the material is in a "solid" state and when selfdesiccation becomes the driving force of autogenous deformations, the application of the maturity concept is likely to give good results, but only for $T \geq 20{ }^{\circ} \mathrm{C}$. The improved maturity concept proposed in this paper has thus been validated within these ranges. Note that higher temperatures than $50{ }^{\circ} \mathrm{C}$ have not been investigated in this study.

Table 3

Values of apparent activation energy $E_{\mathrm{a}}$ for cement pastes with cement CEM I 52.5 and various $\mathrm{W} / \mathrm{C}$

\begin{tabular}{llllll}
\hline W/C & & 0.25 & 0.30 & 0.35 & 0.40 \\
\hline Apparent & Exp. results & 40,500 & 39,450 & 41,040 & 38,155 \\
activation & {$[20]$} & $29,000^{\mathrm{a}}$ & & & \\
energy $E_{\mathrm{a}}$ & & $39,000^{\mathrm{b}}$ & & & \\
$\left(\mathrm{J} \mathrm{mol}^{-1}\right)$ & {$[30]$} & $29,300^{\mathrm{a}}$ & & & \\
& & $36,900^{\mathrm{b}}$ & & & \\
\hline
\end{tabular}

${ }^{\text {a }}$ Before initial Vicat setting time.

b Between initial and final Vicat setting times.
3.4. Comparison between chemical shrinkage and volumetric autogenous shrinkage

According to the literature, the evolutions vs. the age of chemical shrinkage and volumetric autogenous shrinkage are merged at very early age (before setting), but after a couple of hours a deviation appears at the same time as the autogenous shrinkage knee-point previously discussed $[5,6,31,33]$. In the case of the paste with $\mathrm{W} /$ $\mathrm{C}=0.25$ tested here, it seems relevant to investigate how a relatively high temperature may influence the relation between chemical and volumetric autogenous shrinkages. It is well known that, for low $\mathrm{W} / \mathrm{C}$, cement particles are very close to each other. In these conditions, a low hydration level is sufficient to bridge up the distance between the hydrating particles and then give strength and stiffness to the developing microstructure, and consequently, start self-desiccation that can more rapidly become the driving force of deformations. In addition, if the temperature is relatively high, the microstructure will be stabilized even earlier as a result of the temperatureinduced acceleration of the chemical reactions. Therefore, in the case of $\mathrm{W} / \mathrm{C}=0.25$ and $T=50{ }^{\circ} \mathrm{C}$, self-desiccation will occur very early and the period where chemical and autogenous shrinkages are merged will be very short. This is confirmed here and illustrated in Fig. 14, where the experimental results of chemical shrinkage and volumetric autogenous shrinkage obtained for the cement paste cast with $\mathrm{W} / \mathrm{C}=0.25$ and cured at $T=50{ }^{\circ} \mathrm{C}$ are plotted vs. the age, together with initial and final Vicat setting times. It can be seen that the curves diverge before the age of $2 \mathrm{~h}$. 


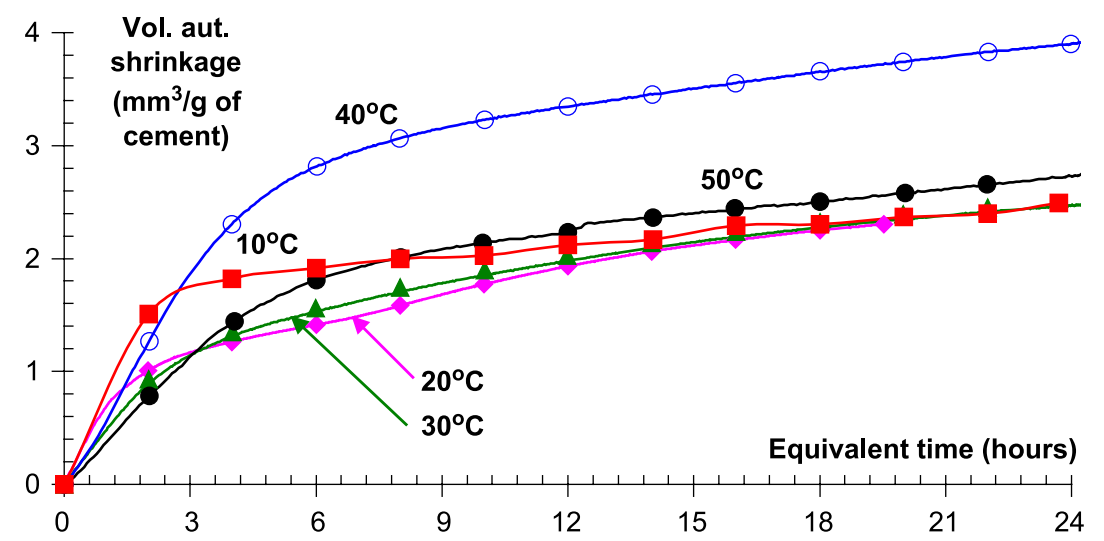

Fig. 12. Application of the maturity concept on volumetric autogenous shrinkage data. Shrinkage values are initialised at final Vicat setting time, according to the improved maturity concept proposed in Section 3.2.

\subsection{Threshold value, micro-macro correlations and determining role of $\mathrm{Ca}(\mathrm{OH})_{2}$}

A threshold located around $\alpha=7 \%$ has been found both at the macro-scale, with respect to early-age deformations, and at the micro-scale, with respect to the calcium hydroxide content (precipitation of $\mathrm{Ca}(\mathrm{OH})_{2}$ detected by TGA). From this threshold, linear fits are displayed as regards calcium hydroxide content vs. degree of hydration (see Figs. 2 and 3 ) and volumetric autogenous shrinkage vs. degree of hydration (see Fig. 8).

It can thus be deduced that the $\mathrm{Ca}(\mathrm{OH})_{2}$ content is a keyparameter as regards the development of autogenous deformations of cement pastes and that volumetric autogenous shrinkage at early age (and for $\mathrm{W} / \mathrm{C}=0.25$ ) is linearly related to this $\mathrm{Ca}(\mathrm{OH})_{2}$ content. This is illustrated in Fig. 15 . Further, the comparison between $\mathrm{Ca}(\mathrm{OH})_{2}$ precipitation threshold and Vicat setting times has exhibited a good correlation, particularly above $T=40{ }^{\circ} \mathrm{C}$ (see Fig. 4). Therefore, $\mathrm{Ca}(\mathrm{OH})_{2}$ precipitation can be considered as a relevant chemical indicator of the setting of cement pastes.

The determining role of $\mathrm{Ca}(\mathrm{OH})_{2}$ will be investigated further in part II of this paper.

\section{Summary and concluding remarks}

Experimental tools for assessing key-parameters have been presented in this paper. These tools can be used in view of designing and optimising mixtures, within the framework of the prediction of early-age deformations and of the prevention of early-age cracking. Various experimental results have been obtained, at early age $(\leq 24 \mathrm{~h})$, by means of these tools on a set of plain cement pastes prepared with the same type I OPC, with $\mathrm{W} / \mathrm{C}$ ranging from 0.25 to 0.40 , and isothermally cured at various temperatures ranging from 10 to $50{ }^{\circ} \mathrm{C}$. In particular, the following temperature effects have been observed:

- An increase in the (isothermal) curing temperature within the range $10-50{ }^{\circ} \mathrm{C}$ yields a decrease in initial and final Vicat setting times and in the respective setting period.

- The application of the maturity concept to chemical shrinkage data obtained at various isothermal curing temperatures has shown that the increase in the initial slope of the chemical shrinkage vs. age plots was only due to kinetic effects of temperature.

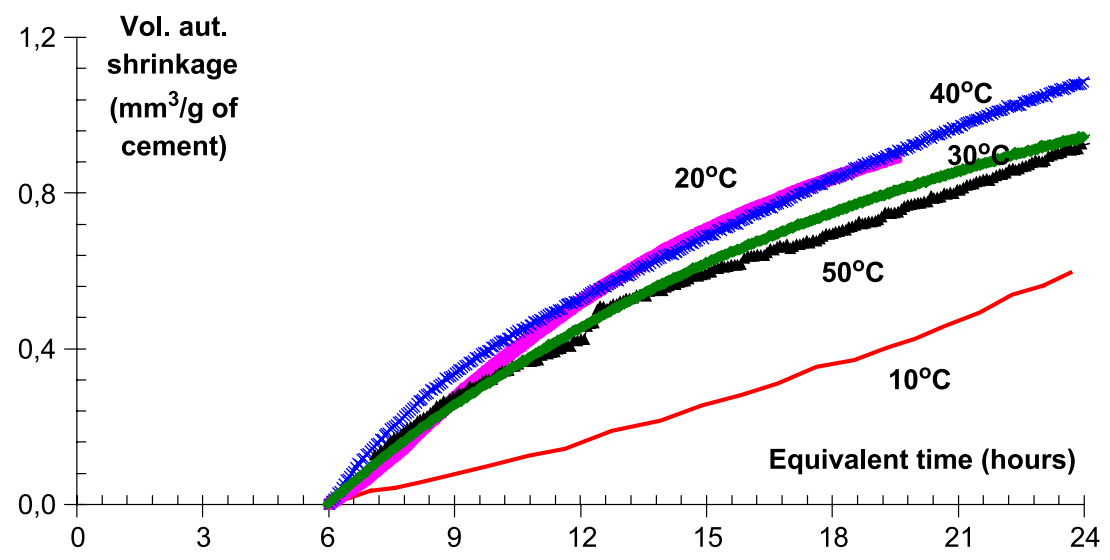

Fig. 13. Application of the maturity concept on volumetric autogenous shrinkage data. Shrinkage values are initialised at $6 \mathrm{~h}$ (equivalent time), i.e. after the "knee-point period". 


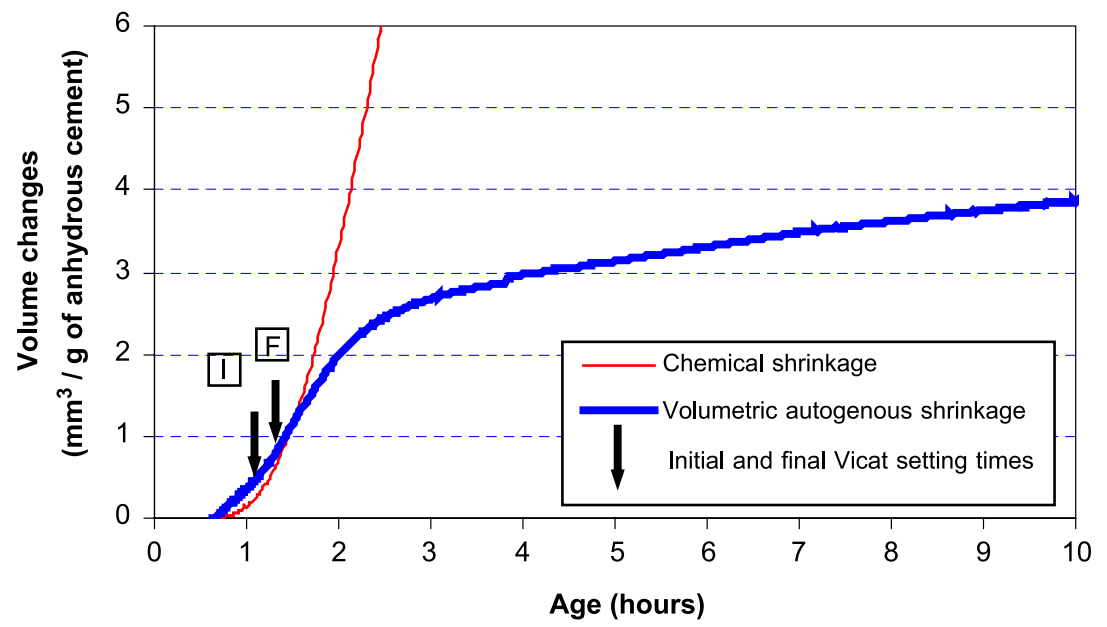

Fig. 14. Comparison between chemical shrinkage and volumetric autogenous shrinkage, for the cement paste with $\mathrm{W} / \mathrm{C}=0.25$ and cured at $T=50{ }^{\circ} \mathrm{C}$.

- Temperature-induced changes are recorded on both the rate and the magnitude of volumetric autogenous shrinkage measured on cement pastes with $\mathrm{W} / \mathrm{C}=0.25$.

- At $T=50{ }^{\circ} \mathrm{C}$, the period where chemical and volumetric autogenous shrinkages are merged is very short for $\mathrm{W} /$ $\mathrm{C}=0.25$. The divergence occurs before $2 \mathrm{~h}$.

Furthermore, practical conclusions can be drawn regarding the use of the maturity concept within the field of concrete technology. The temperature-induced changes, recorded on volumetric autogenous shrinkage data, clearly show the irrelevance of the usual maturity concept (based on a single apparent activation energy) for the prediction of such phenomenon within the whole early-age period 0-24 h. Nevertheless, improved solutions can be suggested on the basis of the results obtained in the study reported in this paper. On the one hand, if the degree of hydration (or the $\mathrm{Ca}(\mathrm{OH})_{2}$ content) can be experimentally assessed within a given temperature range, the "complicated" direct determi- nation of the apparent activation energy can be avoided. Early-age autogenous shrinkage at required temperatures can indeed be derived from the linear relationship existing between shrinkage and the degree of hydration (or the $\mathrm{Ca}(\mathrm{OH})_{2}$ content) within the ad-hoc range, whatever the temperature. On the other hand, if neither the degree of hydration nor the $\mathrm{Ca}(\mathrm{OH})_{2}$ content is available, the maturity concept can be applied after separating the early-age period $0-24 \mathrm{~h}$ in different phases and calculating the respective values of apparent activation energy $E_{\mathrm{a}}$. The experimental results presented in this paper have shown that $E_{\mathrm{a}}$ values could efficiently be assessed through chemical shrinkage data. This takes benefit of an automatic and accurate measurement, which is suitable to pastes with various water-to-cement ratios (contrary to standard Vicat tests). In addition, it has been pointed out that the application of this improved maturity concept could allow the prediction with a correct accuracy of volumetric autogenous shrinkage within the range $20-50{ }^{\circ} \mathrm{C}$, after the "knee-point period".

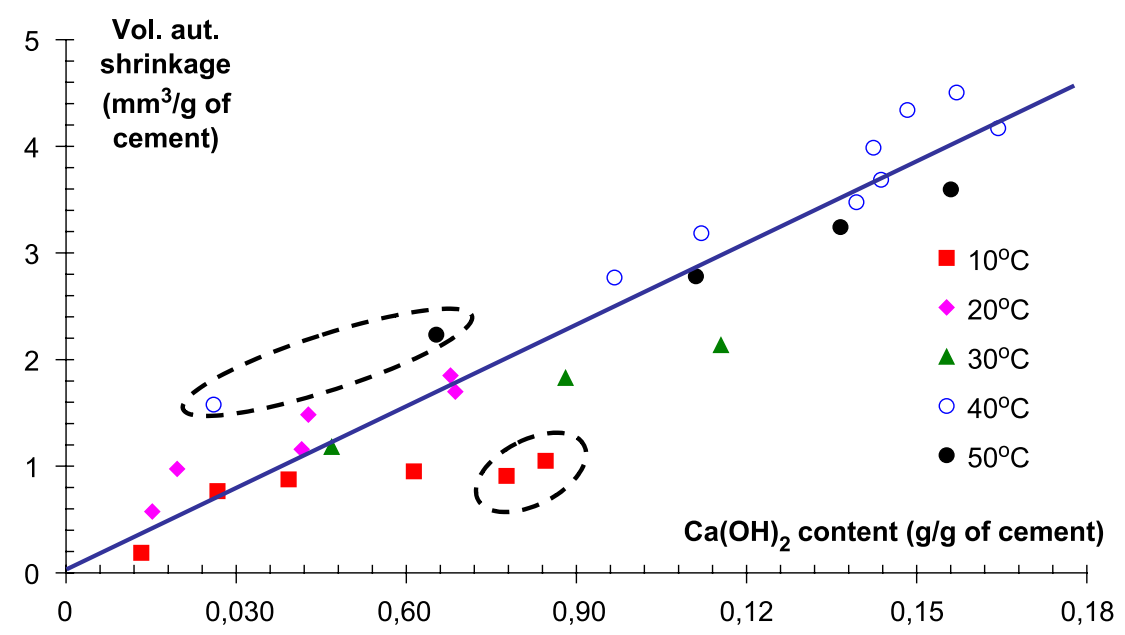

Fig. 15. Volumetric autogenous shrinkage vs. $\mathrm{Ca}(\mathrm{OH})_{2}$ content for cement pastes with $\mathrm{W} / \mathrm{C}=0.25$ and cured at $10,20,30,40$ or $50{ }^{\circ} \mathrm{C}$. Shrinkage values and $\mathrm{Ca}(\mathrm{OH})_{2}$ contents are initialised at $\alpha=7 \%$. 


\section{Acknowledgments}

The authors are grateful to Roger Coué, from IUT de Saint-Nazaire, for his assistance in setting up the experimental devices.

\section{References}

[1] Ø. Bjøntegaard, Thermal dilation and autogenous deformation as driving forces to self-induced stresses in high performance concrete, Ph.D dissertation, NTNU, Trondheim, Norway, 1999, 256 pp.

[2] A. Loukili, D. Chopin, A. Khelidj, J.Y. Le Touzo, A new approach to determine autogenous shrinkage of mortar at an early age considering temperature history, Cem. Concr. Res. 30 (6) (2000) 915-922.

[3] P. Mounanga, A. Khelidj, A. Loukili, V. Baroghel-Bouny, Predicting $\mathrm{Ca}(\mathrm{OH})_{2}$ content and chemical shrinkage of hydrating cement pastes using analytical approach, Cem. Concr. Res. 34 (2) (2004) 255-265.

[4] P. Paulini, A weighing method for cement hydration, in: A.K. Mullick (Ed.), Proceedings of the 9th International Congress on the Chemistry of Cement, National Council for Cement and Building Materials, New Delhi, India, 1992, pp. 248-254

[5] E.J. Sellevold, Ø. Bjøntegaard, H. Justnes, P.A. Dahl, Highperformance concrete: early volume change and cracking tendency, Proceedings of the International RILEM Symposium on Thermal Cracking at Early Ages, Munich, Germany, E. \& F.N. Spon, London, 1994, pp. 229-236.

[6] H. Justnes, A. Van Gemert, F. Verboven, E.J. Sellevold, Total and external chemical shrinkage of low W/C ratio cement pastes, Adv. Cem. Res. 8 (31) (1996) 121-126.

[7] V. Baroghel-Bouny, A. Kheirbek, Effect of mix-parameters on autogenous deformations of cement pastes - microstructural interpretations, Concr. Sci. Eng. 3 (9) (2001) 23-38.

[8] S. Boivin, P. Acker, S. Rigaud, B. Clavaud, Experimental assessment of chemical shrinkage of hydrating cement pastes, in: E.-I. Tazawa (Ed.), Proceedings of the International Workshop on "Autogenous Shrinkage of Concrete" AUTOSHRINK'98, Hiroshima, Japan, 1998, E \& FN Spon, London, 1999, pp. 81-92.

[9] A. Nonat, Interactions between chemical evolution (hydration) and physical evolution (setting) in the case of tricalcium silicate, Mat. Struc. 27 (1994) $187-195$.

[10] A. Nonat, X. Lecoq, S. Gauffinet, Calcium hydroxide concentration in solution: parameter determining the kinetics of the early hydration of tricalcium silicate and the characteristics of the products, in: $\mathrm{H}$. Justnes (Ed.), Proceedings of the 10th International Congress on the Chemistry of Cement, Göteborg, Sweden, 1997.

[11] F.H. Lea, in: P.C. Hewlett (Ed.), Lea's Chemistry of Cement and Concrete, Arnold, London, 1998.

[12] F. Beltzung, F.H. Wittmann, Dissolution of cement and early chemical shrinkage of cement paste, in: V. Baroghel-Bouny, P.C. Aitcin (Eds.), Proceedings of the International RILEM Workshop on Shrinkage of Concrete "Shrinkage 2000", Paris, France, RILEM Publ., Cachan, 2000, pp. 91-97.

[13] L. Barcelo, S. Boivin, P. Acker, J. Toupin, B. Clavaud, Early age shrinkage of concrete: back to physical mechanisms, Concr. Sci. Eng. 3 (10) (2001) 85-91.

[14] H.M. Jennings, A model for the microstructure of calcium silicate hydrate in cement paste, Cem. Concr. Res. 30 (1) (2000) 101-116.

[15] H.M. Jennings, J.J. Thomas, A colloidal interpretation of chemical ageing and deformation mechanisms of the $\mathrm{C}-\mathrm{S}-\mathrm{H}$ gel, Proceedings of 20èmes Journées des Matériaux "Microstructure and micro-macromodelling of concrete and cementitious composites", EPFL, Lausanne, Switzerland, 2001
[16] I.G. Richardson, The nature of $\mathrm{C}-\mathrm{S}-\mathrm{H}$ in hardened cements, Cem. Concr. Res. 29 (8) (1999) 1131-1147.

[17] S.L. Mak, D. Ritchie, A. Taylor, R. Diggins, Temperature effects on early age autogenous shrinkage in high performance concretes, in: E.-I. Tazawa (Ed.), Proceedings of the International Workshop on “Autogenous Shrinkage of Concrete" AUTOSHRINK'98, Hiroshima, Japan, 1998, E \& FN Spon, London, 1999, pp. 155-174.

[18] C. Yahuan, R. Detwiler, Backscattered electron imaging of cement pastes cured at elevated temperatures, Cem. Concr. Res. 25 (3) (1995) $627-638$

[19] K.O. Kjellsen, R. Detwiler, O.E. Gjørv, Development of microstructure in plain cement pastes hydrated at different temperatures, Cem. Concr. Res. 21 (1) (1991) 179-189.

[20] P. Turcry, A. Loukili, L. Barcelo, J.M. Casabonne, Can the maturity concept be used to separate the autogenous shrinkage and thermal deformation of a cement paste at early age? Cem. Concr. Res. 32 (9) (2002) 1443-1450.

[21] P.F. Hansen, J. Pedersen, Maturity computer for controlling curing and hardening of concrete, Nordisk Betong 1 (19) (1977) 19-34.

[22] N.J. Carino, H.S. Lew, The maturity method: from theory to application, in: P.C. Chang (Ed.), Proceedings of the 2001 Structures Congress and Exposition, Washington, DC, USA, 2001, 19 pp.

[23] L. D'Aloïa, Détermination de l'énergie d'activation apparente du béton dans le cadre de l'application de la méthode du temps équivalent à la prévision au jeune âge: approches expérimentales mécaniques et calorimétrique-Simulations numériques (in French), PhD dissertation (INSA: Lyon, France), vol. 1 et 2, 1998, 511 pp.

[24] L. D'Aloïa, G. Chanvillard, Determining the "apparent" activation energy of concrete $\mathrm{Ea}$ - numerical simulations of the heat of hydration of cement, Cem. Concr. Res. 32 (8) (2002) 1277-1289.

[25] L.J. Parrott, M. Geiker, W.A. Gutteridge, D. Killoh, Monitoring Portland cement hydration: comparison of methods, Cem. Concr. Res. 20 (6) (1990) 919-926.

[26] P. Paulini, Chemical shrinkage as indicator for hydraulic bond strength, in: H. Justnes (Ed.), Proceedings of the 10th International Congress on the Chemistry of Cement, Göteborg, Sweden, 1997.

[27] J.I. Escalante-Garcia, J.H. Sharp, The effect of temperature on the early hydration of Portland cement and blended cements, Adv. Cem. Res. 12 (3) (2000) 121-130.

[28] H. Kada-Benameur, E. Wirquin, B. Duthoit, Determination of apparent activation energy of concrete by isothermal calorimetry, Cem. Concr. Res. 30 (2) (2000) 301-305.

[29] K. Van Breugel, Simulation of hydration and formation of structure in hardening cement-based materials, PhD dissertation, T.U. Delft, The Netherlands, 1991.

[30] P. Mounanga, A. Loukili, A. Khelidj, Influence of superplasticizer on activation energy and autogenous shrinkage of a cement paste, Proceedings of the 7th CANMET/ACI International Conference on Superplasticizers and Other Chemical Admixtures in Concrete, Berlin, Germany, 2003.

[31] H. Justnes, F. Clemmens, P. Depuydt, D. Van Gemert, E.J. Sellevold, Correlating the deviation point between external and total chemical shrinkage with the setting time and other characteristics of hydrating cement paste, in: V. Baroghel-Bouny, P.C. Aitcin (Eds.), Proceedings of the International RILEM Workshop on Shrinkage of Concrete "Shrinkage 2000", Paris, France, RILEM Publ., Cachan, 2000, pp. 57-73.

[32] O.M. Jensen, P.F. Hansen, Influence of temperature on autogenous deformation and relative humidity change in hardening cement paste, Cem. Concr. Res. 29 (4) (1999) 567-575.

[33] S. Garcia-Boivin, Retrait au jeune âge du béton-Développement d'une méthode expérimentale et contribution à l'analyse physique du retrait endogène (in French), Ph.D dissertation, Etudes et Recherches des LPC, OA 37, (LCPC, Paris), 2001, 250 pp. 